\title{
Mundo ÁRABE: \\ RETROCESOS, DERROTAS, LUCHAS
}

\section{Santiago Alba Rico}

Escritor

RESUMEN: Tres años después, las revoluciones parecen haber conducido a una derrota total, o al menos a retrocesos tan claros y a veces tan trágicos, que resulta difícil columbrar bajo las involuciones golpistas o los conflictos violentos el original impulso democrático que desencadenó las protestas populares. ¿Qué queda de esas protestas? ¿Qué consecuencias han tenido, a nivel político y geoestratégico para el conjunto de la región? Cualesquiera que sean los retrocesos, lo que no se puede negar es que por primera vez desde la descolonización los pueblos árabes han irrumpido en el escenario de la Historia y con su rebelión, fallida o no, han modificado radicalmente el orden geopolítico de la zona y del mundo.

Palabras clave: revolución, islamismo, democracia, pueblos, geopolítica.

RESUM: Tres anys després, les revolucions pareixen haver conduït a una derrota total, $\mathrm{o}$ almenys a retrocessos tan clars $\mathrm{i}$ a vegades tan tràgics, que resulta difícil albirar davall les involucions colpistes o els conflictes violents l'original impuls democràtic que va desencadenar les protestes populars. Què queda d'aquelles protestes? Quines conseqüències han tingut, en l'àmbit polític i geoestratègic per al conjunt de la regió? Siguen quins siguen els retrocessos, el que no es pot negar és que per primera vegada des de la descolonització els pobles àrabs han irromput en l'escenari de la Història i amb la seua rebel·lió, fallida o no, han modificat radicalment l'ordre geopolític de la zona i del món.

Paraules clau: revolució, islamisme, democràcia, pobles, geopolítica. 
ABSTRACT: Three years on, the revolutions appear to have led to total defeat, or at least setbacks that are so clear and sometimes so tragic that it is difficult to discern the original democratic impulse that sparked the popular protests beneath the regressive coups or violent conflicts. What remains of these protests? What consequences have they had, at a political and geo-strategic level, for the whole region? Whatever the setbacks, it cannot be denied that for the first time since decolonisation the Arab peoples have come onto the stage of history and through their revolt, failed or otherwise, they have radically changed the geopolitical order of the region and the world.

KEYWORDs: revolution, Islamism, democracy, peoples, geopolitics.

$\mathrm{C}$ uatro años después del desencadenamiento de las revoluciones, intifadas y revueltas árabes que sacudieron la región e incubaron sueños de rebeldía en todo el mundo, domina la sensación no infundada de una derrota en todas las líneas o, al menos, de un retroceso traumático y a veces trágico. La llamada primavera árabe habría desembocado — una fórmula acunada con tanta frivolidad como la primera - en un invierno islamista o se habría extraviado en guerras civiles sectarias, golpes de Estado casi inevitables y juegos geoestratégicos de guerra fría. Curiosamente, la izquierda más estalibana y la derecha más islamofóbica acaban compartiendo la imagen sombría de un mundo irrecuperable para la democracia y la revolución.

Esta visión contiene, es cierto, una parte de verdad: podemos decir que las revoluciones árabes se pervirtieron en Libia, se atascaron en Siria y murieron en Egipto; y que se pudren ahora con la brutal ofensiva del Estado Islámico en Irak y en toda la región. Pero conviene ajustar nuestros análisis a una realidad muy compleja y volátil en la que los pueblos -árabes y otros, como amazigh o kurdos - siguen jugando un papel muy activo y, al mismo tiempo, no dejarse llevar por esquemas geopolíticos excesivamente simplificadores. Cualesquiera que sean los innegables retrocesos en un proceso fecundo en esperanzas iniciales, sólo el sectarismo doctrinal menos elegante podría negar 
asimismo las enormes transformaciones, algunas poco estimulantes, introducidas en la región por el despertar de sus pueblos. La dimensión popular y la política dejan cada vez más su lugar a la geoestratégica, pero ni sería justo desdeñar desde fuera el sacrificio de los que dieron y siguen dando su vida por un poco de dignidad y justicia social, ni honesto hacer abstracción de la nueva fluidez y multilateralidad en el marco de las relaciones de fuerza interimperialistas a nivel regional. Las revoluciones árabes siguen siendo uno de los acontecimientos mayores de nuestro siglo y sus consecuencias se siguen desplegando tras los bastidores y muchas de ellas no se harán evidentes sino con el paso de los años.

En todo caso, para comprender qué está ocurriendo y quizás qué va a ocurrir, es necesario tratar de comprender antes qué ha pasado y qué efectos podemos ya medir.

\section{Deshielo de la guerra fría e irrupción de pueblos}

Como sabemos, el 17 de diciembre de 2010 se produjo en una ciudad del interior de Túnez un acontecimiento ya mitológico: la inmolación de Mohamed Bouazizi, un vendedor ambulante de verduras humillado por la policía. Este gesto de desesperación desencadenó un movimiento sísmico que determinó el derrocamiento del dictador Ben Ali el 14 de enero de 2011 y una larguísima sacudida, de Mauritania al Golfo, que derribó algunos regímenes (Egipto, Libia, Yemen) y amenazó, de una manera u otra, en mayor o menor medida, todos los demás (Alba Rico, 2011; Rodríguez, 2011).

Teocracias o falsas repúblicas, todos los regímenes de la zona compartían rasgos comunes y todos los pueblos de la zona sufrían males comunes: de la humillación cotidiana y la represión política a la desesperación económica. Por eso inicialmente, como en una orquesta de millones de instrumentos, lo común se impuso de manera casi mecánica, por contagio epidémico. No cabe duda de que una de las causas sin las cuales nunca se habrían producido los levantamientos populares en el mundo árabe tiene que ver con la economía: el aumento de los precios de los alimentos, el aumento del paro, el incremento de la pobreza y la marginación social. No en todos los países, es verdad, la situación era igualmente apremiante: menos en Libia o Baréin, más en Egipto o 
Siria o Yemen o Túnez. Lo que experimentaron todos los países por igual en la última década - incluida la Libia ilusoriamente opulenta de Gadafi - fue un proceso de liberalización económica con privatización de recursos que acabó por imprimir características comunes en todas partes: agravamiento de las diferencias sociales, monopolio mafioso de la riqueza en unas pocas manos $\mathrm{y}$, como consecuencia de este dominio económico corrupto y familiar, incremento también de la represión política y policial (Achcar, 2013). El término dignidad (karama) resume muy bien esta rebelión contra un conjunto integrado de causas económicas y motivos político-sociales en el que el malestar económico y el malestar social se mezclaban de manera casi indiscernible. Los árabes estaban tratando de sacudirse — están tratando de sacudirse — la «miseria vital»: el peso de un sistema tentacular que regía su vida cotidiana y los empobrecía en todos los sentidos y que, además de reprimirlos o torturarlos, los humillaba y despreciaba. Y los degradaba moralmente (Naïr, 2013).

Esta sacudida se inscribe en una historia y un contexto regional muy concretos. Tras la segunda guerra mundial, el pacto del Quincy entre EEUU y Arabia Saudí, con el consiguiente control imperialista petrolero y la difusión de la versión más retrógrada y reaccionaria del islam (el wahabismo), y el establecimiento del Estado de Israel van a generar, en el marco de la Guerra Fría, la respuesta del nacionalismo árabe (Redissi, 2007). La oposición a estas tres fuerzas, en efecto, condujo en buena parte del mundo árabe (Siria, Irak, Egipto, Túnez, Argelia, Libia, el propio Yemen) al establecimiento de regímenes panarabistas autoritarios, pero con una fuerte vertiente social. No por casualidad los países mencionados son precisamente los más afectados por las revueltas de 2011. Todos los estudiosos, por ejemplo, coinciden en relacionar la «ola de terrorismo islámico» de los años 90 no sólo con la guerra de Afganistán sino con las políticas sociales de estos regímenes que llevaron a las aulas a miles de hijos de campesinos y de proletarios que se dieron de bruces contra el fracaso económico, político y social: un vasto sector de población juvenil que no podía volver al campo ni emplear sus conocimientos en una economía fallida, se sintió excluido y redundante y pasó a nutrir las filas islamistas (Carré, 1993). En la primera década de este siglo, el fracaso a su vez del islamismo más violento y los cambios tecnológicos globales, con la integración de estos jóvenes marginados en un imaginario global, confirió un nuevo sello al malestar social de los árabes: digamos que los jóvenes 
árabes con diploma (cuyos porcentajes de paro superan en muchos casos el $50 \%$, por encima de las altísimas medias nacionales) comenzaron a percibir su exclusión social más como una agresión a su juventud que a su identidad o su religión. Pero lo que caracteriza a la última década no es un aumento de los jóvenes con estudios, sino más bien una degradación notable de la calidad de la formación y de la enseñanza, con una fuerte elitización de los estudios $\mathrm{y}$, por tanto, de las posibilidades también de integración laboral y reconocimiento social. El neoliberalismo radical de la última década produce, pues, un doble fenómeno: descualificación y desvalorización de los títulos académicos y creciente exposición subjetiva a estímulos de consumo y deseos globales de orden capitalista. Esa mezcla no podía no resultar explosiva.

Las revueltas árabes son inseparables de este orden regional compuesto de cuatro elementos (hegemonía petrolera estadounidense, islamismo wahabí, sionismo israelí y panarabismo autoritario) pero también de la descomposición del enfrentamiento bipolar de la Guerra Fría, que sólo engañosamente parece entregar la hegemonía a los EEUU. De hecho, la soledad en la cúspide de los estadounidenses, fruto de su victoria en la Guerra Fría, ha durado muy poco. No hay que olvidar que fue esa derrota de la URSs en 1989 la que paradójicamente está poniendo en dificultades hoy a los vencedores. Cuando pensamos en la caída del Muro y en la victoria estadounidense siempre pensamos en las llamadas revoluciones de colores y en el avance avasallador del capitalismo en el Este europeo; pero los procesos democratizadores de América Latina, por ejemplo, que tanto incomodan a los EEUU y que comenzaron también en esas fechas, habrían sido imposibles en el marco de la confrontación de bloques. Desde comienzos de los años 90 se produce en todo el mundo, en efecto, una demanda general de democracia al margen de los enfrentamientos ideológicos binarios; una demanda popular que resultó sospechosa - y beneficiosa para los EEUU — en la órbita ex soviética (Yugoslavia, Georgia, la Ucrania de 2004), donde el anticomunismo contiene, nos guste o no, un impulso también democrático, pero una demanda que cuestionó en cambio el poder de los EEUU en América Latina (Venezuela, Ecuador, Bolivia, etc.), donde la democracia contiene un impulso también socialista. Ese deshielo de la Guerra Fría alcanzó con retraso en 2011 el mundo árabe, una zona literalmente congelada durante décadas bajo el hielo de la dictadura y la geoestrategia, y sigue levantando olas un poco por todas partes a medida 
que la crisis mina al mismo tiempo las condiciones de supervivencia y los marcos de legitimidad.

\section{Reacción y contrarrevolución: derrumbe del modelo turco-catarí}

Lo cierto es que, como he dicho más arriba, todos los países de la zona compartían rasgos comunes que tenían que ver con el carácter dictatorial del poder político y la naturaleza neoliberal-mafiosa del régimen económico. Pero como demuestra la propia reacción de las potencias occidentales frente a los levantamientos, no todos ellos jugaban el mismo papel en el tablero geoestratégico de la región; y como demuestra el mayor o menor éxito de las revueltas, cada uno de ellos tenía y tiene sus propias especificidades locales. Egipto y Túnez se parecían mucho, tanto por su composición social como por su superior articulación política; los dos países habían ensayado la revolución de 2011 con huelgas y protestas en los años anteriores (en 2008, en Mahala Kubra y en la cuenca minera respectivamente); y, si en el primer caso era el ejército el pilar securitario del régimen y en el otro la policía, en ambos casos el ejército fue decisivo al abandonar a Moubarak y Ben Ali en un plazo relativamente corto de tiempo. Ahora este parecido ha estado a punto de costar caro a Túnez. El golpe de Estado del general Sissi en Egipto el 3 de julio de 2013 produjo un efecto bumerán en Túnez, donde intentó aplicarse el mismo modelo para derrocar al Gobierno del partido islamista Ennahda. La inteligencia pragmática de los islamistas y las presiones europeas evitaron en el último momento lo que hubiera significado muy probablemente el cierre definitivo del ciclo revolucionario. La dimisión del Gobierno de Ali Laraidh y la aprobación de la primera constitución liberal del mundo árabe (enero 2014) concedieron un respiro a la transición tunecina y mantienen viva una luciérnaga de esperanza en toda la zona en un momento de claro retroceso. Las elecciones de octubre de 2014, con el retorno democrático del antiguo régimen, dejan fuera, en todo caso, las esperanzas de esa mayoría social que hizo la revolución y, precozmente desencantada, no participó en los comicios.

Libia y Siria, a su vez, se parecían bastante; en los dos casos, como señala Gilbert Achcar (Achcar, 2013), la fusión entre régimen y familia gobernante 
era tan completa que los cuerpos de seguridad no tenían ninguna autonomía que pudiera, en un momento dado, inclinarse del lado de la revuelta. Por eso mismo también el grado de violencia empleado por las dictaduras, y por los rebeldes, ha sido mucho mayor. A esto hay que añadir la intervención occidental, directa o indirecta, pero mucho más clara y determinante que en otros escenarios. Hay, por lo tanto, una primera fase de las revueltas en la que prima lo común sobre lo específico (la reclamación de dignidad frente a autoritarismos mafiosos), pero enseguida, en virtud de las propias historias nacionales y de la intervención occidental, las especificidades pasaron a un primer plano.

Esta inesperada irrupción de los pueblos, en cualquier caso, abrió una modesta pero luminosa oportunidad en la zona. Yo la llamaría sin lugar a dudas revolución. No fue una revolución socialista y no fue dirigida por la izquierda. Tampoco fue una revolución islámica y los islamistas tuvieron asimismo un papel muy reducido. Pero como fue una revolución democrática, salió a flote la verdadera relación de fuerzas en la zona - reprimida durante décadas- y las elecciones, allí donde las hubo, llevaron al gobierno a los partidos islamistas de la órbita de los Hermanos Musulmanes. Tanto la izquierda de la región, avejentada y estalinista, como los partidos islamistas, que incubaban sueños de califato, cedieron a la presión popular y adoptaron sinceros programas democráticos. Los fulul de la dictadura, a su vez, se reciclaron en demócratas y, desde distintas organizaciones y partidos, en condiciones sin precedentes de libertad de expresión y reunión, comenzaron a trabajar para recobrar el poder.

Un año después de la inmolación de Bouazizi, un modelo parecía imponerse de manera irresistible en el nuevo mundo árabe en gestación a partir de las intifadas populares: el que debía llevar al poder, por la vía democrática, a los islamistas moderados asociados a la constelación de los Hermanos Musulmanes. Así ocurrió en Túnez con Nahda y en Egipto con Justicia y Libertad; en Libia no ganaron las elecciones, pero pasaron a constituir la fuerza mejor articulada y la más influyente; en Siria, dominaban también la oposición en el exilio hasta hace pocos meses. Este modelo era apoyado desde Catar, enano aupado en enormes zancos financieros, y sobre todo desde Turquía, país gobernado por el islamista AKP al que la primavera árabe brindó la oportunidad de restablecer su influencia regional histórica, en un viraje político que muchos analistas llamaron «neo-otomano». La imparable ascensión de los 
Hermanos Musulmanes —en cierto sentido, normalización de una relación de fuerzas reprimida o clandestina - explica sin duda la ruptura de Erdogan con Siria, con el que mantenía excelentes relaciones de vecindad, pero también, por ejemplo, el cambio de posición de la organización palestina Hamas frente al régimen de Bachar Al-Assad, del que era aliado y huésped hasta hace dos años.

Pues bien, este modelo, que prometía democratizar y estabilizar la región sin rupturas económicas y que contaba por eso con el apoyo refunfuñón de las potencias occidentales, reveló muy pronto sus limitaciones bajo la triple presión de la crisis económica global, los conflictos geoestratégicos y la movilización popular. El modelo turco o, lo que es lo mismo, el modelo de los Hermanos Musulmanes, se ha desmoronado muy rápidamente, pero no como resultado del fracaso del partido AKP gobernante en Turquía sino de la intervención contrarrevolucionaria de fuerzas internas y externas, a menudo enfrentadas entre sí, en el contexto de la región. Esta intervención tiene distintos tiempos y adopta formas muy distintas en los distintos escenarios, a medida que las protestas se han extendido o estancado. La resolución 1971 de la ONU en febrero de 2011 y la posterior intervención de la OTAN a favor y en contra de la revuelta libia fue posible porque Gadafi estaba completamente aislado y generó por eso pocas fracturas ideológicas y geoestratégicas entre las potencias y entre los propios partidos locales. El caso de Siria es bien diferente. Por su centralidad estratégica en el eje llamado «chií» o de «resistencia» (la secuencia Irán-Irak-Siria-Hizbullah), la legítima revuelta contra la dictadura dinástica de los Assad, que comenzó en Deraa en marzo de 2011, se transformó en pocos meses en una batalla multinacional con intervención indirecta o directa de distintos países: Catar, Turquía, Arabia Saudí y, menos, la uE y los EEUU del lado de los rebeldes; y Rusia, Irán, Irak y Hizbullah del lado del Gobierno. Como claro indicio de la nueva complejidad y de la invalidez de los análisis campistas, hay que recordar que sólo los aliados de Bachar Al-Assad forman realmente un bloque. La diferencia de intereses y de implicación en la trinchera rebelde se revela en la variedad ideológica de las milicias, muchas veces enfrentadas entre sí, que combaten el régimen (Burgat, 2013). En todo caso, la agonía siria, con la recuperación de posiciones sobre el terreno y de legitimidad internacional por parte de la dictadura (tras el acuerdo ruso-estadounidense sobre armas químicas en agosto de 2013 y las conversaciones de 
Ginebra en enero de 2014), ha cuestionado seriamente el proyecto regional de Erdogan al tiempo que ha dejado casi fuera de juego, o al menos del proscenio, la revuelta democrática original. El AKP, que abandonó su alianza con Siria creyendo jugar una carta ganadora, se ve hoy directamente amenazado por la «cuestión siria», que está minando su apoyo interior, sobre todo como consecuencia de la presencia de miles de refugiados, y reduciendo su influencia exterior. Los recientes intercambios de visitas entre Ankara y Teherán prueban que Erdogan se está viendo obligado a revisar su estrategia en Siria.

Años después, sin embargo, cumple evitar dos ilusiones al hablar de Siria: la de que no ha pasado nada desde las primeras manifestaciones pacíficas y la de que ya no hay otra cosa que una guerra sectaria en Siria. Creo que, para conjurar estas dos tentaciones, es muy bueno escuchar a los sirios que quedan vivos y, entre ellos, al admirable Yassin Al-Haj Saleh, un intelectual marxista del que puede leerse una reciente entrevista en traducción al castellano (http:// rebelion.org/noticia.php?id=182153).

¿Qué ha pasado en estos tres años? Ha pasado que la dictadura ha matado, encarcelado, torturado, hecho desaparecer y/o expulsado del país a decenas de miles de líderes y militantes democráticos — mientras liberaba o dejaba tranquilos a los feroces yihadistas que decía combatir y gracias a cuya existencia trataba de legitimarse en el exterior.

Ha pasado que la política de destrucción sistemática, brutal, total, aplicada por el régimen — con bombardeos aéreos a población civil, hambrunas inducidas, torturas y empleo más que probable de armas químicas - ha facilitado el protagonismo militar del yihadismo, a veces tan salvaje como el propio régimen, en el terreno militar.

Ha pasado que la oposición siria reconocida, controlada por el exilio y por Arabia Saudí y Catar (enfrentados entre sí), ha sido incapaz de representar y unir al frente revolucionario del interior, contribuyendo al retroceso de la sociedad civil y al crecimiento del internacionalismo yihadista, el único que desgraciadamente ha llegado al país. La conquista de Mosul en Irak (agosto 2014) y el asedio a Kobane en Siria (desde septiembre) por parte del Estado Islámico, con sus 15.000 extranjeros enfervorizados (muchos de ellos europeos) da buena medida del éxito del régimen sirio en dejar fuera de juego a la 
oposición democrática y de la ambigüedad de los EEUU, que produjo el caos en Irak y no lo evitó en Siria.

Ha pasado que, mientras Arabia Saudí, Catar y Turquía alimentaban con armas, hombres y dinero a los grupos yihadistas y Rusia, Irán, Irak y Hizbullah apoyaban con armas, hombres y dinero a la dictadura, las fuerzas democráticas, laicas e islamistas moderadas no recibían ninguna clase de ayuda solidaria, ni militar ni política, por parte de las presuntas democracias occidentales ni por parte de la presunta izquierda mundial. Mientras el imperialismo estadounidense amagaba una intervención - que muy pocos querían - para acabar imponiendo, en favor de Israel, el desarme químico de la dictadura y el desarme convencional de los rebeldes, legitimando así a la propia dictadura, el antiimperialismo oficial sostenía el gobierno de Al-Assad y se hacía cómplice de sus crímenes. La intervención ahora de los aviones estadounidenses frente al Estado Islámico sólo va a servir para consolidar aún más el régimen de Assad y alimentar el apoyo al yihadismo radical.

Ha pasado que muchos intelectuales y partidos de izquierda, de manera sabihonda y con escasa sensibilidad ética, han recomendado a sus referentes en Siria, perseguidos durante años por la dinastía Al-Assad, que aceptaran el mal menor de la dictadura y se sometieran al poder colonial interno que los estaba matando (cuando no los bombardeaban virtualmente desde Madrid, Caracas u Ottawa acusándoles de traidores, imperialistas o mercenarios).

Ha pasado que la derecha y la izquierda, a nivel de Gobierno, partidos y medios de comunicación, ha acabado convergiendo, salvo excepciones, en el mito de la lucha antiterrorista para abandonar o ignorar u ocultar la resistencia heroica y el dolor inconmensurable de millones de sirios que quieren paz, libertad y dignidad. Son los sirios los que están luchando contra el terrorismo, el del régimen y el de el EI, ante el silencio estrepitoso, cuando no la complicidad expresa, de todas las fuerzas y todas las potencias. Como para revelar la nueva promiscuidad geoestratégica y el acuerdo entre las potencias, mencionemos el recentísimo acercamiento (mayo 2014) entre Irán y Arabia Saudí, enemigos encarnizados hasta ayer y que hoy buscan conjuntamente una solución al problema sirio - en detrimento, obviamente, de los pueblos- Terrible mundo éste en el que lo mejor que les puede ocurrir ya a los sirios es que dos dictaduras religiosas se pongan de acuerdo para acabar con la violencia. 
Ha pasado, en fin, que, tres años y medio después, dos evidencias se imponen rotundamente: la de que las posibilidades de autodeterminación para Siria han disminuido trágicamente en el avispero geopolítico interimperialista y la de que, de todos modos, cualquier esperanza de construcción nacional democrática, reconciliación y desyihadización pasa hoy, como en marzo de 2011, por el derrocamiento de Bachar Al-Assad y de su criminal régimen fascista.

\section{El golpe de Estado egipcio}

Pero el modelo turco-catarí, y la normalización democrática en la región, recibió su zarpazo más duro el 3 de julio de 2013 en Egipto tras el brutal golpe de Estado que derrocó a Mohamed Mursi, dirigente de los Hermanos Musulmanes y primer presidente civil de la historia de Egipto (Almodóvar, 2013). El ejército egipcio, máximo receptor de ayuda económica de los EEUU y columna vertebral de la economía nacional, garante de los acuerdos de Camp David con Israel, se convirtió así en el motor de una acelerada reversión del tsunami popular desencadenado en enero de 2011, reversión que, de vuelta a su lugar de origen, ha estado a punto de sumergir también a Túnez, cuna de las revoluciones árabes, y a Libia, más silenciada, donde la nueva tentativa golpista del general Hiftar (mayo del 2014) apunta directamente a la rama local de la Hermandad, sostén del nuevo gobierno de Maaitiq. La posibilidad de una normalización democrática a través de la integración de los islamismos moderados, muy real hace sólo un año, amenaza con truncarse de la peor manera, a la argelina y hoy sólo se mantiene más o menos viva en el pequeño país del norte de África, cuya importancia es más bien simbólica. Frente a esa normalización se renuevan los viejos ciclos de dictadura - represión radicalización - criminalización - dictadura contra los que se levantaron los pueblos en 2011.

El golpe del general Sissi marca el verdadero punto de inflexión. Sería difícil exagerar los horrores de la dictadura impuesta por el general Sissi hace ahora un año. El frío resumen en cifras resulta ya escalofriante: en torno a 3.000 muertos a manos de la policía o el ejército, miles de heridos de bala, 20.000 personas encarceladas, 21 prisioneros muertos bajo tortura, 1.212 sen- 
tencias de muerte en juicios sumarísimos colectivos que —más allá del escarnio a la idea misma de justicia - revelan la voluntad del nuevo viejo régimen de aplastar toda forma de resistencia (o de presionar hasta el límite de cara a futuras negociaciones con la Hermandad, cuyos dirigentes están hoy todos en prisión o en el exilio).

Los que pensaban que la junta militar sólo iba a perseguir a los islamistas, experimentan hoy en propia carne hasta qué punto estaban equivocados: abogados y activistas de izquierda, miembros del partido marxista Socialistas Revolucionarios, los jóvenes del Movimiento 6 de Abril — protagonista de la revolución del 25 de Enero y hoy ilegalizado - son detenidos, reprimidos y acosados por las nuevas viejas autoridades.

Los que pensaban que, en cualquier caso, era un golpe de Estado nacionalista y laico (de inspiración nasserista) saben hoy quiénes son los valedores promiscuos del nuevo viejo régimen: Arabia Saudí, los Emiratos, Israel, la dictadura siria, Rusia, los propios EEUU, cuyas teatrales vacilaciones iniciales han dejado sitio enseguida a un restablecimiento de la normalidad, refrendado por la reciente entrega de helicópteros Apache al ejército egipcio. Si en términos geoestratégicos las potencias perdedoras son Turquía y Catar, el golpe de Estado contra los Hermanos Musulmanes reúne en una misma trinchera a todas las fuerzas - tan dispares entre sí- interesadas en enterrar a toda prisa hasta las sombras de un cambio democrático en el mundo árabe.

En este contexto de represión y dictadura, se celebraron el 26 de mayo de 2014 - apenas 10 días antes que en Siria - las así llamadas «elecciones presidenciales», en realidad un plebiscito romano para atornillar en el trono al nuevo viejo caudillo. El desprecio por toda legitimidad revolucionaria o democrática se expresó en la campaña en favor del faraónico Pinochet de consenso del nuevo viejo Egipto. Hay que recordar, en efecto, que el ex presidente Hosni Moubarak, sacado de prisión por la junta militar, salió también en televisión para expresar su sostén al general golpista; y que la ultraderecha islamista del partido Nur - financiado por Arabia Saudí - hizo lo propio en un comunicado oficial en el que pedía el voto para el jefe del ejército. Las escasas voces discordantes, como la de Abu-1-Futuh, dirigente del partido Masr Qouia, ex candidato a las presidenciales de 2012 y crítico, al mismo tiempo, con la junta militar y con los Hermanos Musulmanes, no han estado presentes 
en los medios de comunicación ni representadas en los comicios del 26 de mayo, en los que ha habido una altísima abstención - que hay que adivinar bajo los índices manipulados de participación oficial.

\section{La relativa esperanza tunecina}

En enero de 2014, tras un tortuoso zigzag de dos años, la Asamblea Constituyente tunecina aprobó la nueva constitución del país con 200 votos a favor, 12 en contra y 2 abstenciones. No se puede rebajar la importancia de este texto, ni del impulso que ha llevado hasta él, pero conviene de entrada dejar claras dos cosas. La primera es que no se trata de una constitución revolucionaria sino de una constitución liberal en la que - y no es en absoluto insignificante - se garantizan derechos y libertades, pero se protege poco la soberanía nacional sobre los recursos materiales. La segunda es que podrá decirse que el texto final es más liberal que la ideología dominante del partido Ennahda y que sin las movilizaciones de la sociedad civil, las presiones de la UE y las amenazas regionales no se habría aprobado, pero no puede olvidarse que la Carta Magna es también, o sobre todo, obra de Ennahda, como lo demuestra la firma del primer ministro cesante, Ali Lareydh, al pie de sus 146 artículos. Aún más: es necesario recordar que esa oposición, de izquierdas y de derechas, que se ha querido atribuir los méritos de la redacción y que felizmente acabó uniéndose a la emoción constituyente, hasta el mes de diciembre de 2013 pedía la disolución de la Asamblea y apostaba públicamente por «una vía egipcia a la democracia». Si algo tiene de esperanzador todavía el proceso tunecino es precisamente el hecho de que la primera constitución democrática y civil del mundo árabe ha sido redactada bajo un Gobierno de mayoría islamista. Como decía el sociólogo Chukri Hmed (Hmed, 2014), su aprobación, mientras Siria y Egipto se pudren en la guerra y la tiranía, sirve al menos para desmentir el dañino cliché occidental, tan funcional a los dictadores locales, que declara incompatibles mundo árabe y democracia. Desmiente también, añadiría yo, el no menos dañino, y no menos interesado y potencialmente dictatorial cliché, que declara incompatibles democracia e islamismo.

Mientras el régimen egipcio aprobó una constitución retrógrada a la sombra de una dictadura militar, Túnez aprueba su constitución a través del con- 
senso en el marco de un proceso constituyente más bien pacífico y relativamente legítimo. Aquí en Túnez nació la mal llamada primavera árabe y aquí parecía ir a morir. Túnez tiene poca importancia geoestratégica, pero mucha importancia simbólica, para los grandes y para los pequeños. Para los grandes es un laboratorio de intervención. Para los pequeños es la esperanza de un nuevo mundo árabe más libre y más justo. Su resistencia, cuando parecía destinada a rodar hacia el pasado, es el resultado de muchos factores, algunos no del todo luminosos, pero ilumina, en cualquier caso, una región otra vez atenazada por la oscuridad. Su ejemplo, una vez más, como en 2011, puede insuflar un nuevo aliento a las fuerzas democráticas del mundo árabe.

Pero también aquí — hay que advertirlo—, más sigilosos, menos violentos, las tentativas involucionistas son evidentes. La aprobación de la Constitución en enero de 2014 cerró un conflicto político muy peligroso, pero abrió paradójicamente el paso al regreso del viejo régimen enquistado en los aparatos del Estado sin depurar.

Un síntoma alarmante dio la alerta el 12 de abril de 2014 cuando el Tribunal Militar de Apelación confirmó la condena de Ben Alí, refugiado en Arabia Saudí, pero revisó las de sus esbirros en prisión. Condenados en primera instancia a penas oscilantes entre 10 y 37 años de cárcel como responsables de la represión de las jornadas revolucionarias de diciembre, enero y febrero de 2011, el tribunal ha recalificado los cargos como «homicidio involuntario» y ha impuesto a los acusados penas reducidísimas que, en la mayor parte de los casos, han cumplido ya. Como escribe el analista Saif Soudani (Soudani, 2014), el veredicto y la propia escena del proceso «vienen a barrer de un manotazo la superioridad de la justicia revolucionaria», sustituida por una «justicia militar que tenía ese día un aire egipcio, espónsor de facto de la contrarrevolución». Y como denuncia la periodista Patrizia Mancini (Mancini, 2014), residente en Túnez y responsable de la página Tunisia-in-red, la sentencia reveló también «la soledad de las familias de las víctimas y de los heridos de la revolución». Más allá de las declaraciones oficiales de rechazo a la sentencia o del cuestionamiento del carácter militar del tribunal, todas las fuerzas políticas, incluido el Frente Popular, parecen olvidar el papel «constituyente» - el realmente constituyente - de todas esas muertes heroicas (casi 400) que piden a gritos nuevas leyes, nuevos policías y nuevos jueces; 
y parecen olvidar también la Ley de Justicia Transicional, aprobada a trompicones en diciembre de 2013 y cuya aplicación permitiría apartar o disolver los tribunales militares y constituir nuevos marcos jurídicos «de transición» capaces de ajustar cuentas con el pasado y anticipar un futuro más garantista y democrático.

Otro síntoma sombrío, paralelo e inverso, es el arresto y procesamiento en los últimos meses de decenas de jóvenes, algunos de ellos parientes de mártires o heridos ellos mismos durante la revolución y que son acusados ahora de diferentes delitos «contra la seguridad pública»: ataques a policías o centros policiales, formación de bandas, insultos a la autoridad o difamación. «Su único crimen», escribe Henda Chennaoui, «es el de haber reivindicado justicia y dignidad con los mismos métodos que hasta hace no mucho tiempo se calificaban de "revolucionarios"». Los habitantes de Regueb, Meknassi y Jelma han organizado un comité de apoyo a los detenidos, mientras que un grupo de jóvenes ha lanzado una iniciativa en Facebook bajo el reivindicativo título «También nosotros hemos quemado una comisaría». Una vez más, los jóvenes son criminalizados, como bajo Ben Ali, con las leyes de Ben Ali, ante el silencio de los partidos y del sindicato UGTT, que han olvidado todos los agravios, políticos y económicos, que desencadenaron la revuelta popular contra la dictadura.

Entre tanto, el gobierno tecnócrata, no-ideológico, de Mehdi Jumaa, aprovechó el consenso impuesto desde el exterior, y aceptado casi sin resistencias por todas las fuerzas, para llegar a acuerdos económicos con la UE y el FMI, renovar concesiones a empresas extranjeras (salinas o petróleo) al margen de la constitución y anticipar «medidas de ajuste» que se podrían haber evitado con una auditoría y la negativa a pagar el servicio de una deuda que el propio parlamento europeo declaró hace dos años «ilegítima». Los veredictos del 12 de abril, la rehabilitación mediática y política de figuras y empresarios del antiguo régimen, la corrupción que retoña, la represión que sigue, todo parece indicar que un consenso de élites a la española, basado en el principio de «mucha libertad económica y sólo la libertad política compatible con ella», va poco a poco cerrando los márgenes aún abiertos para operar una verdadera ruptura. Así parecen demostrarlo los resultados de las elecciones del pasado 24 de octubre, en las que Nidé Tunis, el partido del octogenario ex ministro 
de Bourguiba, Qaid Essebsi, vertedero de todas las fuerzas del pasado, se hizo con una amplia mayoría de gobierno.

\section{Conclusiones}

Tres años después del comienzo de las revoluciones árabes los retrocesos son evidentes y las derrotas también. Podemos, en todo caso, enumerar rápidamente algunas conclusiones:

- Las revoluciones árabes cogieron a contrapié a todos los actores, incluidos los EEUU, y en términos geoestratégicos han acelerado el debilitamiento de los EEUU como actor principal en la zona.

- El nuevo orden geoestratégico refuerza el papel de potencias mundiales como Rusia y de potencias locales, como Irán, Arabia Saudí y - ahora en descenso - Turquía y Catar. Las alianzas, en todo caso, son cambiantes, muy volátiles y están muy sujetas a los intereses inmediatos sobre el terreno. No hay bloques sino - digamos-sexo ocasional muy promiscuo entre todos los actores.

- El verdadero motor de la contrarrevolución no han sido Europa y los EEUU, interesados más bien en una estabilidad regional que pasaba por resignarse al protagonismo democrático de los Hermanos Musulmanes y sus ramas locales (y a la dictadura siria), sino Arabia Saudí con su golpe de Estado regional contra la Hermandad y, del otro lado, Irán con su apoyo — reforzado por Hizbullah— al feroz régimen sirio.

- Por eso mismo es absurdo hablar de un invierno islamista. Los islamistas moderados no gobiernan en ningún país, ni siquiera en aquellos (como Egipto o Túnez) donde ganaron las elecciones y, si el islamismo yihadista recupera terreno tras haber casi desaparecido, se debe justamente a este retorno contrarrevolucionario al pasado en el que, una vez más, las dictaduras teocráticas y las laicas se dan la mano para aplastar a los pueblos y generar el caos. Dictaduras, yihadismo e imperialismo (gemelos que viven de la respiración de sus hermanos y que van siempre de la mano en esta zona del mundo) están en realidad muertos. Y si los zombis pueden gobernar el mundo eternamente, cumple recordar, en todo caso, que han quedado - histórica, política y éticamente - fuera de juego. 
- La vieja izquierda árabe, como la europea, ha quedado fuera de juego como consecuencia de su elitismo y su oportunismo (http://rebelion. org/noticia.php?id=181599) y, en su lugar, habrá que buscar nuevos marcos organizativos y discursivos que integren movimientos sociales y bases populares en una lucha que concilie soberanía nacional y cultural, justicia social, democracia auténtica, respeto por las minorías étnicas y lingüísticas e igualdad de género. Los pueblos árabes eligieron el peor momento para reivindicar democracia y dignidad - cuando retrocedía en todo el mundo- y un avispero de fuerzas dispares y enfrentadas entre sí se ha abatido sobre ellos para frenar sus reivindicaciones, pero los retrocesos y las derrotas no pueden hacer olvidar las luchas — ni el luminoso momento de la irrupción colectiva — que siguen vivas bajo las cenizas. Apenas sople el aire, las brasas volverán a atizar y avivar el fuego.

\section{Referencias}

AchCar, G. (2013): Le peuple veut, Actes Sud, Paris.

Alba Rico, S. (2011): Túnez, la revolución, Hiru, Hondarribia.

Almodovar, M. (2013): Egipto tras la barricada, Virus, Barcelona.

Burgat, F. (2013): Pas de primptemps pour la Syrie, La Découverte, Paris.

CARré, O. (1993): Le nationalisme arabe, Fayard, Paris.

Нмed, Сн. (2014): Sur la transition en Tunisie. En: <http://www.tunisiainred.org/tir/?p=3516>.

MancinI, P. (2014): Il verdetto della vergogna. En: < http://www.tunisiainred. org/tir/?p=3756>.

NAÏr, S. (2013): ¿Por qué se rebelan?, Clave Intelectual, Madrid.

REDissi, H. (2007): Le pacte de Nadjd, Seuil, Paris.

Rodríguez, O. (2012): Yo muero hoy, Debate, Barcelona.

Soudani, S. (2014): Le verdict de la honte. En: <http://nawaat.org/portail/2014/04/13/le-verdict-de-la-honte/>. 
